\title{
The effect of anatomic variations of circle of Willis on cerebral blood distribution during posture change from supination to standing: A model study
}

\author{
Chi Zhang ${ }^{\mathrm{a}}$, Shuyu $\mathrm{Li}^{\mathrm{a}}$, Fang Pu ${ }^{\mathrm{a}, \mathrm{b}}$, Yubo Fan ${ }^{\mathrm{a}, \mathrm{b}}$ and Deyu $\mathrm{Li}^{\mathrm{a}}$,b,* \\ ${ }^{a}$ Key Laboratory for Biomechanics and Mechanobiology of Ministry of Education, School of \\ Biological Science and Medical Engineering, Beihang University, Beijing 100191, China \\ ${ }^{b}$ State Key Lab of Virtual Reality of Technology and Systems, Beihang University, Beijing 100191, \\ China
}

\begin{abstract}
The anatomic variation of Circle of Willis $(\mathrm{CoW})$ has great impact on its compensatory capacity during stroke and cerebral ischemia. In the present study, a series of lumped parameter models were developed and used to simulate the effect of postural changes on the cerebral blood flow in ICA stenosis patients with different anatomic variants of the CoW. The results showed that the asymmetric distribution of cerebral blood flow caused by stenosis was attenuated in standing position in complete and half-complete CoW. However, in incomplete $\mathrm{CoW}$, the decrease in blood flow in the ipsilateral cerebral arteries caused by unilateral ICA stenosis was dramatic in both supine and standing positions, a likely result of inadequate collateral circulation within the CoW. In conclusion, the anatomic variation of CoW plays a significant role in maintaining the balance of cerebral blood supply in patients with ICA stenosis, especially during postural change.
\end{abstract}

Keywords: Circle of Willis, internal carotid artery stenosis, anatomic variation, lumped parameter model, posture change

\begin{tabular}{ll|ll} 
Glossary & & \\
CoW & circle of Willis & ICA & internal carotid artery \\
R & resistance & MCA & middle cerebral artery \\
L & inertia & ACA & anterior cerebral artery \\
C & compliance & PCA & posterior cerebral artery \\
CCA & common carotid artery & ACoA & anterior communicating artery \\
ECA & external carotid artery & PCoA & posterior communicating artery
\end{tabular}

\footnotetext{
${ }^{*}$ Corresponding author: Deyu LI, School of Biological Science and Medical Engineering, Beihang University, No. 37 Xueyuan Road, Haidian District, Beijing 100191, China. Tel.: +8 610 82339093; Fax: +8 610 82339093; E-mail: deyuli@buaa.edu.cn.
}

0959-2989/14/\$27.50 @ 2014 - IOS Press and the authors.

This article is published with Open Access and distributed under the terms of the Creative Commons Attribution and Non-Commercial License. 


\section{Introduction}

During stroke and other forms of brain ischemia, the CoW network of cerebral arteries ensures sufficient and stable blood supply to the affected parts of the brain. The basis for this lies in the CoW's ring-like structure, which maintains collateral circulation against cerebral stenosis or occlusion. Unfortunately, studies have shown that the full ring-like structure of the CoW is present in only half of the patients $[1,2]$. Consequently, anatomic variations in the CoW reduce the compensatory ability and increase the risk for stroke [3]. Therefore, investigating on the effect of morphological variations of CoW on the cerebral blood flow has significant implications for understanding the mechanism of stroke and for planning intracranial neurosurgery or vascular surgery $[4,5]$.

Several studies have been conducted to investigate the association between the compensatory capability andanatomic variations [6-9]. The symmetry of the cerebral blood distribution was considered as an indicator to assess the compensatory capability of the CoW [10]. Recently, the dynamic response of cerebral blood flow to postural change was also considered as an effective way to analyze the function of cerebral arteries and the auto-regulation of the cardiovascular system [11]. However, the compensatory function of the CoW may be associated with some cerebral artery diseases, such as ICA stenosis [12]. The correlation between ICA stenosis, anatomic variations of the $\mathrm{CoW}$, and cerebral blood flow remains to be studied.

In the present study, the distribution of blood flow in CoW with anatomic variations and different degree of unilateral ICA stenosis was simulated during the postural change from supine to standing position. This study may be valuable for evaluating the significance of the anatomic variation of $\mathrm{CoW}$ in patients with ICA stenosis.

\section{Methods}

\subsection{Mathematical model}

The mathematical model was based on the linear, 1D equations of pressure and flow wave propagation in a compliant vessel, which would be analogous to an electric component that consists of resistance $(\mathrm{R})$, inertia $(\mathrm{L})$ and compliance $(\mathrm{C})$. The value of $\mathrm{R}, \mathrm{L}$, and $\mathrm{C}$ were calculated using equations based on the geometrical and mechanical data of the vessel $[13,14]$ :

$$
\begin{aligned}
& R=\frac{8 \mu l}{\pi r^{4}} \\
& L=\frac{9 \rho l}{4 \pi r^{2}} \\
& C=\frac{3 \pi l r^{3}}{2 E h}
\end{aligned}
$$

where $1, \mathrm{r}$, and $\mathrm{h}$ represented the length, radius and thickness of the vessel, respectively; $\mathrm{E}$ was the elastic parameter of the vasculature; $\rho$ was the blood density; $\mu$ was the viscosity of blood. The detailed method for the modeling was introduced in the previous study [15]. Accordingly, a model including aorta, carotid, vertebral, and CoW was established (Figure 1). The parameters of the arteries 
in this model are shown in Table 1 [16]. Four models were simulated, representing different anatomic variations of the CoW. Model A denotes the complete CoW; B represents the absence of ACoA; C represents the absence of LPCoA; and D represents the absence of both ACoA and LPCoA. Our previous study demonstrated that the absence of ACoA and ipsilateral PCoA would aggravate the decrease in cerebral blood flow in patients with unilateral ICA stenosis. In the present study, the four models were simulated to assess the effect of postural changes on the cerebral blood flow in ICA stenosis patients with different anatomic variants of the CoW. The degree of stenosis was set to $0 \%$ (no stenosis), $20 \%, 50 \%, 70 \%$, and $90 \%$ area reduction of the LICA. I. The parameters of LICA. I (R, $\mathrm{L}$, and $\mathrm{C}$ ) were changed according to the extent of stenosis in the simulation.

The input condition of the model was set as the flow rate at the inlet of the ascending aorta. The waveform of the flow rate was shown in Figure 2. The cardiac cycle was set as $0.8 \mathrm{~s}$.

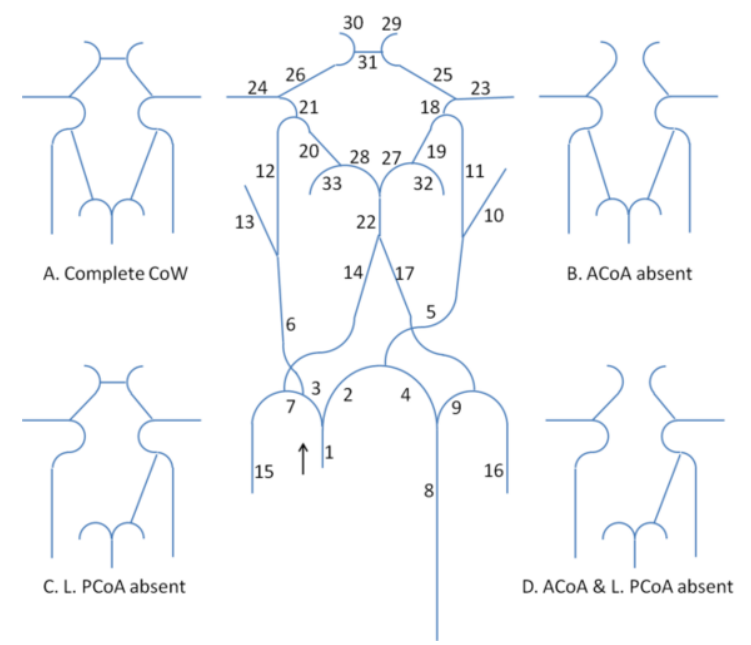

Fig. 1. Schematic representation of the lumped parameter model used to simulate cerebral blood flow and the anatomic variations. The following arteries are included: aorta $(1,2,4,8)$, brachiocephalic $(3)$, cubclavians $(7,9)$, brachials $(15,16)$, carotids $(5,6,10,11,12,13,18,21)$, vertebrals $(14,17)$, basilar (22), PCoAs (19, 20), ACoA (31), (middle cerebral arteries) MCAs (23, 24), (anterior cerebral arteries) ACAs (25, 26, 29, 30), and (posterior cerebral arteries) PCAs (27, 28, 32, 33). The four models (A to D) show the anatomic variations of CoW studied in this paper.

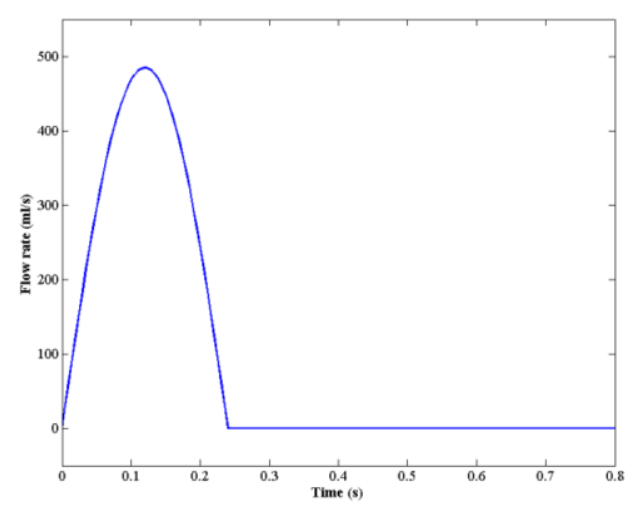

Fig. 2. The waveform of the flow rate at the inlet of aorta. 
Table 1

The parameters of the arteries in the model

\begin{tabular}{|c|c|c|c|c|c|c|c|c|}
\hline $\begin{array}{l}\text { Arterial } \\
\text { segment }\end{array}$ & $\begin{array}{l}1 \\
(\mathrm{~cm})\end{array}$ & $\begin{array}{l}\mathrm{r} \\
(\mathrm{cm})\end{array}$ & $\begin{array}{l}\mathrm{h} \\
(\mathrm{cm})\end{array}$ & $\begin{array}{l}\mathrm{E} \\
\left(10^{6} \mathrm{~Pa}\right)\end{array}$ & $\begin{array}{l}\mathrm{R} \\
(\mathrm{mmHg} \bullet \mathrm{s} / \mathrm{ml})\end{array}$ & $\begin{array}{l}\mathrm{L} \\
\left(\mathrm{mmHg} \cdot \mathrm{s}^{2} / \mathrm{ml}\right)\end{array}$ & $\begin{array}{l}\mathrm{C} \\
(\mathrm{ml} / \mathrm{mmHg})\end{array}$ & $\begin{array}{l}\text { Peripheral } \\
\text { resistance } \\
(\mathrm{mmHg} \bullet \mathrm{s} / \mathrm{ml}) \\
\end{array}$ \\
\hline 1. Ascending aorta & 4.0 & 1.45 & 0.163 & 0.4 & $6.92 \mathrm{E}-05$ & $1.08 \mathrm{E}-03$ & $1.17 \mathrm{E}-01$ & \\
\hline 2. Aorta arch I & 3.0 & 1.12 & 0.126 & 0.4 & $1.46 \mathrm{E}-04$ & $1.36 \mathrm{E}-03$ & $5.25 \mathrm{E}-02$ & \\
\hline 3. Brachiocephalic & 3.5 & 0.62 & 0.080 & 0.4 & $1.81 \mathrm{E}-03$ & $5.17 \mathrm{E}-03$ & $1.64 \mathrm{E}-02$ & \\
\hline 4. Aorta arch II & 3.9 & 1.07 & 0.115 & 0.4 & $2.27 \mathrm{E}-04$ & $1.93 \mathrm{E}-03$ & $6.52 \mathrm{E}-02$ & \\
\hline 5. LCCA & 20.8 & 0.37 & 0.063 & 0.4 & $8.49 \mathrm{E}-02$ & $8.63 \mathrm{E}-02$ & $2.62 \mathrm{E}-02$ & \\
\hline 6. RCCA & 17.7 & 0.37 & 0.063 & 0.4 & $7.22 \mathrm{E}-02$ & 7.34E-02 & $2.23 \mathrm{E}-02$ & \\
\hline 7. R. subclavian & 3.4 & 0.42 & 0.067 & 0.4 & $8.12 \mathrm{E}-03$ & $1.08 \mathrm{E}-02$ & $6.03 \mathrm{E}-03$ & \\
\hline 8. Thoracic aorta & 15.6 & 1.00 & 0.110 & 0.4 & $1.20 \mathrm{E}-03$ & 8.87E-03 & $2.22 \mathrm{E}-01$ & $6.75 \mathrm{E}-01$ \\
\hline 9. L. subclavian & 3.4 & 0.42 & 0.067 & 0.4 & $8.12 \mathrm{E}-03$ & $1.08 \mathrm{E}-02$ & $6.03 \mathrm{E}-03$ & \\
\hline 10. L. ext. carotid & 17.7 & 0.15 & 0.042 & 0.8 & $2.67 \mathrm{E}+00$ & 4.47E-01 & $1.12 \mathrm{E}-03$ & $2.04 \mathrm{E}+01$ \\
\hline 11. LICA.I & 23.7 & 0.20 & 0.050 & 0.8 & $1.13 \mathrm{E}+00$ & $3.36 \mathrm{E}-01$ & $2.98 \mathrm{E}-03$ & \\
\hline 12. RICA. I & 23.7 & 0.20 & 0.050 & 0.8 & $1.13 \mathrm{E}+00$ & $3.36 \mathrm{E}-01$ & $2.98 \mathrm{E}-03$ & \\
\hline 13. R ext. carotid & 17.7 & 0.15 & 0.042 & 0.8 & $2.67 \mathrm{E}+00$ & 4.47E-01 & $1.12 \mathrm{E}-03$ & $2.04 \mathrm{E}+01$ \\
\hline 14. R. vertebral & 14.8 & 0.19 & 0.045 & 0.8 & $8.68 \mathrm{E}-01$ & $2.33 \mathrm{E}-01$ & $1.77 \mathrm{E}-03$ & \\
\hline 15. R. brachial & 23.5 & 0.27 & 0.054 & 0.4 & $3.19 \mathrm{E}-01$ & $1.78 \mathrm{E}-01$ & $1.41 \mathrm{E}-02$ & $1.01 \mathrm{E}+01$ \\
\hline 16. L. brachial & 23.5 & 0.27 & 0.054 & 0.4 & $3.19 \mathrm{E}-01$ & $1.78 \mathrm{E}-01$ & $1.41 \mathrm{E}-02$ & $1.01 \mathrm{E}+01$ \\
\hline 17. L. vertebral & 14.8 & 0.19 & 0.045 & 0.8 & $8.68 \mathrm{E}-01$ & $2.33 \mathrm{E}-01$ & $1.77 \mathrm{E}-03$ & \\
\hline 18. LICA. II & 0.5 & 0.20 & 0.050 & 1.6 & $2.39 \mathrm{E}-02$ & $7.10 \mathrm{E}-03$ & $3.14 \mathrm{E}-05$ & \\
\hline 19. L. PCoA & 1.5 & 0.07 & 0.018 & 1.6 & $4.04 \mathrm{E}+00$ & $1.60 \mathrm{E}-01$ & $1.27 \mathrm{E}-05$ & \\
\hline 20. R. PCoA & 1.5 & 0.07 & 0.018 & 1.6 & $4.04 \mathrm{E}+00$ & $1.60 \mathrm{E}-01$ & $1.27 \mathrm{E}-05$ & \\
\hline 21. RICA. II & 0.5 & 0.20 & 0.050 & 1.6 & $2.39 \mathrm{E}-02$ & $7.10 \mathrm{E}-03$ & $3.14 \mathrm{E}-05$ & \\
\hline 22. Basilar & 2.9 & 0.16 & 0.040 & 1.6 & $3.22 \mathrm{E}-01$ & $6.27 \mathrm{E}-02$ & $1.21 \mathrm{E}-04$ & \\
\hline 23. LMCA & 11.9 & 0.14 & 0.036 & 1.6 & $2.18 \mathrm{E}+00$ & $3.30 \mathrm{E}-01$ & $3.79 \mathrm{E}-04$ & $2.24 \mathrm{E}+01$ \\
\hline 24. RMCA & 11.9 & 0.14 & 0.036 & 1.6 & $2.18 \mathrm{E}+00$ & $3.30 \mathrm{E}-01$ & $3.79 \mathrm{E}-04$ & $2.24 \mathrm{E}+01$ \\
\hline 25. L ACA. I & 1.2 & 0.12 & 0.029 & 1.6 & $4.90 \mathrm{E}-01$ & $4.98 \mathrm{E}-02$ & $2.60 \mathrm{E}-05$ & \\
\hline 26. RACA. I & 1.2 & 0.12 & 0.029 & 1.6 & $4.90 \mathrm{E}-01$ & $4.98 \mathrm{E}-02$ & $2.60 \mathrm{E}-05$ & \\
\hline 27. LPCA. I & 0.5 & 0.11 & 0.027 & 1.6 & $2.92 \mathrm{E}-01$ & $2.48 \mathrm{E}-02$ & $8.90 \mathrm{E}-06$ & \\
\hline 28. RPCA. I & 0.5 & 0.11 & 0.027 & 1.6 & $2.92 \mathrm{E}-01$ & $2.48 \mathrm{E}-02$ & $8.90 \mathrm{E}-06$ & \\
\hline 29. LACA. II & 10.3 & 0.12 & 0.030 & 1.6 & $3.80 \mathrm{E}+00$ & $4.06 \mathrm{E}-01$ & $2.33 \mathrm{E}-04$ & $3.18 \mathrm{E}+01$ \\
\hline 30. RACA. II & 10.3 & 0.12 & 0.030 & 1.6 & $3.80 \mathrm{E}+00$ & $4.06 \mathrm{E}-01$ & $2.33 \mathrm{E}-04$ & $3.18 \mathrm{E}+01$ \\
\hline 31. ACoA & 0.3 & 0.07 & 0.019 & 1.6 & $7.65 \mathrm{E}-01$ & $3.11 \mathrm{E}-02$ & $2.51 \mathrm{E}-06$ & \\
\hline 32. LPCA. II & 8.6 & 0.11 & 0.026 & 1.6 & $5.41 \mathrm{E}+00$ & $4.43 \mathrm{E}-01$ & $1.50 \mathrm{E}-04$ & $4.16 \mathrm{E}+01$ \\
\hline 33. RPCA. II & 8.6 & 0.11 & 0.026 & 1.6 & $5.41 \mathrm{E}+00$ & 4.43E-01 & $1.50 \mathrm{E}-04$ & $4.16 \mathrm{E}+01$ \\
\hline
\end{tabular}

\subsection{Simulation of postural change}

The postural change from supine to standing position was simulated in this study (Figure 3). The effect of postural change can be attributed to gravity. When a person stands up from supine position, the blood is redistributed by the gravity. Therefore, an element standing for the gravity of blood was 
considered in some important arteries, such as descending aorta, CCAs, ICAs, ECAs, and vertebral arteries. Because these arteries were mainly developed vertically, the effect of gravity was primarily expressed by the blood pressure along these arteries. Consequently, for these arteries, the pressure and flow rate was simulated by the circuit shown in Figure 4 . The pressure and flow rate along the artery was expressed as:

$$
\begin{aligned}
& C \frac{d P_{o}}{d t}=Q_{i}-Q_{o} \\
& L \frac{d Q_{i}}{d t}=P_{i}-P_{o}-P_{G}-Q_{i} R
\end{aligned}
$$

where $P_{i}$ and $P_{o}$ were the blood pressure at the inlet and outlet of the artery; $I_{i}$ and $I_{o}$ were the flow rate of the inflow and outflow of the artery; $\mathrm{P}_{\mathrm{G}}$ denoted the blood pressure change caused by gravity.

The simulation was conducted for 40 cardiac cycles. The posture change was set at the end of the 20th cycle $(\mathrm{t}=16 \mathrm{~s})$. The value of $\mathrm{P}_{\mathrm{G}}$ was set as:

$$
P_{G}=\left\{\begin{array}{l}
0 \quad t<16 \\
\varepsilon \rho g l \quad t \geq 16
\end{array}\right.
$$

where $\mathrm{g}$ denoted the gravity of acceleration, $9.8 \mathrm{~m} / \mathrm{s}^{2} ; \varepsilon$ denoted the direction of the blood flow through the artery. If blood flowed downward in the artery, the value of $\varepsilon$ was -1 ; otherwise, the value was 1 . Therefore, the effect of postural change was simulated by changes in the $P_{G}$ value.

\section{Results}

Simulation results at the supination position were validated by transcranial Doppler examination [15]. The results of the cerebral blood flow in Model A with no stenosis are shown in Figure 5. The decrease of the flow rate at the time of $16 \mathrm{~s}$ indicated the effect of posture change from supine to standing position. Because of the postural change, the blood was redistributed in the body. The gravity of blood drives more blood into the descending aorta and lower limb arteries. As a result, the flow rate in the cerebral arteries was decreased.

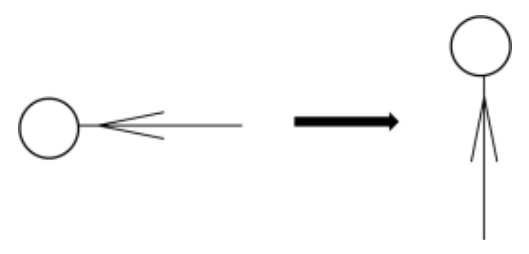

Fig. 3. Simulation setup of the posture change from supine to standing position.

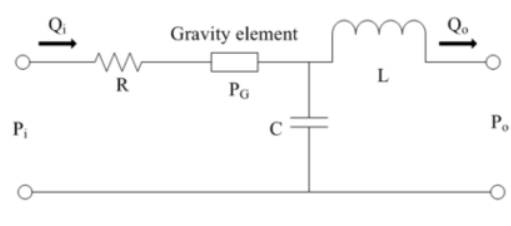

Fig. 4. The circuit analogous to the artery considering the effect of gravity. 

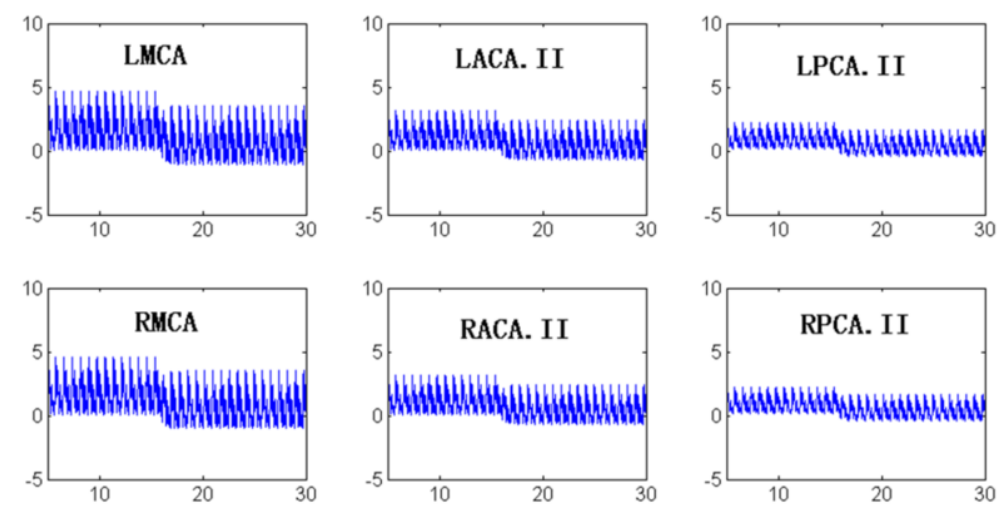

Fig. 5. The flow rate change in the cerebral arteries during the posture change. The Y axis denotes the flow rate ( $\mathrm{ml} / \mathrm{s}$ ); while the $\mathrm{X}$ axis denotes the time (s).

The averaged flow rate through a cardiac cycle in cerebral arteries is shown in Figure 6. Since the effect of the stenosis in LICA is mainly expressed by the flow rate in the ipsilateral arteries of the anterior circulation, only the flow rate for LMCA and LACA. II are shown. In Model A, the decrease inflow rate caused by postural changes was not influenced by the degree of ICA stenosis. Although the flow rate in the LMCA and LACA, II declined slightly in the supine position, the flow rate difference among varying degrees of stenosis was reduced after postural change, indicating that blood flow is less dependent on the degree of stenosis in the standing position. Model B and C showed the same pattern for the changes in blood flow during the change in posture. However, in Model D, the decrease in cerebral blood flow was more evident in both supine and standing positions, suggesting that the cerebral blood flow was heavily influenced by stenosis in both postures.

The blood distribution in CoW is shown in Figure 7. In Model A with no stenosis, the distribution of cerebral blood flow was symmetrical in the CoW regardless of changes in position (Figure 7 I). In addition, the effect of ICA stenosis was not significant, because the distribution of blood flow was slightly asymmetric (Figure 7 II). Standing position attenuated the asymmetric distribution in the CoW. On the other hand, in Model D without any stenosis, the blood distribution remained symmetric during postural change (Figure 7 III). But in Model D with ICA stenosis, the asymmetric distribution of cerebral blood flow was evident for both supine and standing positions (Figure 7 IV). Taken together, the asymmetric distribution of blood flow in CoW should be attributed to the dual absence of ACoA and PCoA, as well as ICA stenosis.

\section{Discussion and conclusion}

Lumped parameter models of CoW were developed in the present study to simulate the effect of ICA stenosis and the anatomic variation of CoW on the cerebral blood flow during postural change. The simulation results showed that the postural change from supine to standing position decreased the flow rate in cerebral arteries. In addition, the decrease would not be aggravated by the unilateral ICA stenosis in complete (Model A) and half-complete (Model B and C) CoW. Only in Model D, where both ACoA and LPCoA are absent, do we see further decrease in cerebral flow rate with increasing degrees of ICA stenosis. 

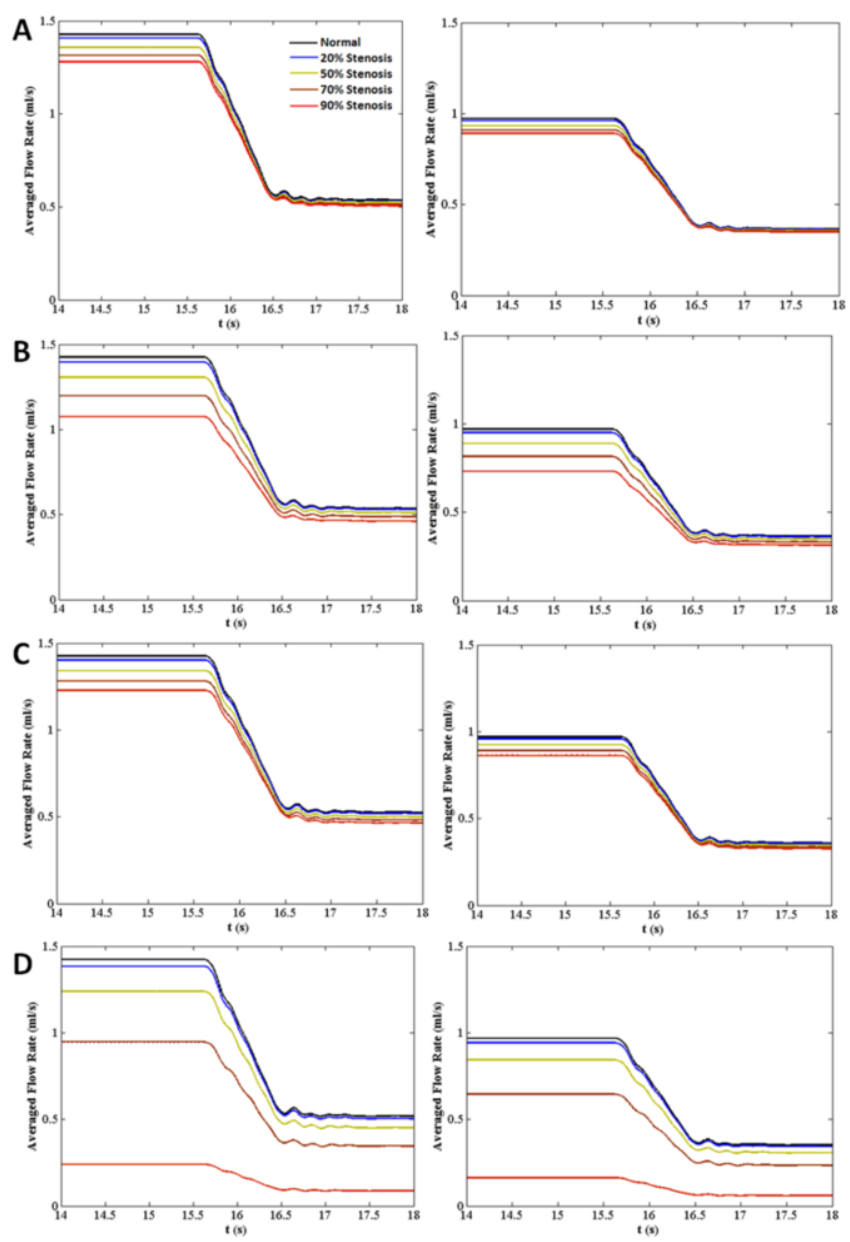

Fig. 6. The change of the averaged flow rate through a cardiac cycle during the posture change. The left column shows the averaged flow rate in LMCA; while the right one in LACA. II. The lines A to D denote Model A to D.

The effect of ICA stenosis on the cerebral blood flow has been researched for years. Many studies proposed that ICA stenosis might increase the incidence of stroke and other cerebral artery diseases, by decreasing the flow rate in cerebral arteries $[17,18]$. Our results suggested that in subjects with complete CoW (Model A), even with $90 \%$ stenosis of the ICA, the decrease inflow rate in the ipsilateral MCA and ACA was minor (no more than 17\% and 10\%). In half-complete CoW (Model B and $\mathrm{C}$ ), the decrease inflow rate in the ipsilateral MCA and ACA caused by ICA stenosis was slightly aggravated by the anatomic variation of CoW, but was still limited (less than $24 \%$ ). In addition, the decrease incerebral blood flow caused by ICA stenosis was attenuated in standing position (less than $13 \%$ ), indicating that in the standing position, even $90 \%$ unilateral ICA stenosis had limited effect on the decrease in cerebral blood flow in complete and half-complete CoW. The decrease in flow rate in CoW caused by ICA stenosis was significant only in incomplete CoW (Model D). The flow rate decrease in LMCA caused by stenosis was obvious before and after postural change ( $84 \%$ vs. $81 \%$ ), as similar changes were also observed in ACA ( $83 \%$ vs. $82 \%)$. The results suggested that the anatomic variation of CoW might play an important role in the stabilization of cerebral blood flow in patients with unilateral ICA stenosis, especially during postural change. 


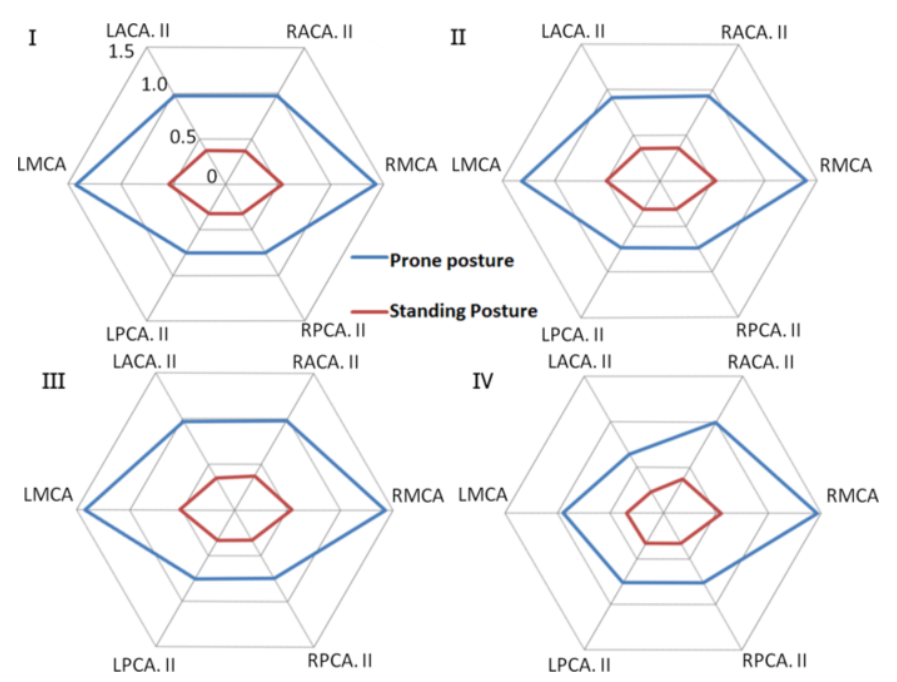

Fig. 7. The distribution of cerebral blood flow during the posture change. I. Model A with normal LICA; II. Model A with $70 \%$ stenotic LICA; III. Model D with normal LICA; IV. Model D with 70\% stenotic LICA.

In fact, the anatomic variation of CoW has attracted many researchers. The importance of ACoA was first addressed by Cassot in cerebral hemodynamics with ICA stenosis [6]. The significance of communicating arteries was systematically analyzed by Alastruey et al. $[16,19]$. We also found that the absence of ACoA and ipsilateral PCoA simultaneously would cause dramatic decrease in blood flow in the anterior circulation in patients with unilateral ICA stenosis. In the present study, the phenomenon was again validated by the simulation of postural change. In Model A, B, and C, the decrease in cerebral blood flow was attenuated by the collateral circulation during postural change; while in Model D, the incomplete structure of CoW prevented the compensatory function of the CoW. In complete and half-complete $\mathrm{CoW}$, the asymmetric distribution was attenuated in the standing position; while in incomplete CoW, it was obvious in both supine and standing positions, indicating that incomplete $\mathrm{CoW}$ would pose greater risk for the patients with ICA stenosis, especially during postural changes.

In our study on the blood flow in CoW, some limitations have to be addressed. First, the auto-regulation of cerebral arteries was not simulated in this model. Although the dilation of cerebral arteries would attenuate the decrease of cerebral flow rate, the effect of this auto-regulation is limited [20]. Secondly, the neuro-regulation of the cardiovascular system was not considered. The decrease of blood flow caused by postural change would recover gradually by the neuro-regulation of the cardiovascular system [11]. However, the aim of this study was to investigate differences in cerebral artery flow rate between two postures. The process of cerebral flow rate changes in subjects with different CoW structures during postural changes would be the subject of future studies.

In conclusion, the flow rate in CoW with different structures and different degrees of ICA stenosis during postural change was simulated by lumped parameter model. The asymmetric distribution of cerebral blood flow caused by unilateral ICA stenosis was attenuated in standing position in complete and half-complete CoW. However, incomplete CoW prevented its compensatory function and caused further decrease in blood flow in the anterior circulation upon changing from supine to standing position. Therefore, the incomplete structure of $\mathrm{CoW}$, which may increase the risk for patients with ICA stenosis, should be considered as a screening factor for stroke and other cerebrovascular diseases. 


\section{Acknowledgement}

This study was supported by National Natural Science Foundation (No. 11302019 and No. 61190122), Beijing Natural Science Foundation (No. 7144220), National Key Technology R \& D Program (2012BAI19B04), and State Key Laboratory of Virtual Reality Technology and Systems.

\section{References}

[1] B.J. Alpers, R.G. Berry and R.M. Paddison, Anatomical studies of the circle of Willis in normal brain, Archives of Neurology 81 (1959), 409-418.

[2] S. Kamath, Observations on the length and diameter of vessel forming the circle of Willis, Journal of Anatomy $\mathbf{1 3 3}$ (1981), 419-423.

[3] B. Hillen, A.H. Drinkenburg, H.W. Hoogstraten and L. Post, Analysis of flow and vascular resistance in a model of the circle of Willis, Journal of Biomechanics 21 (1988), 807-814.

[4] J.R. Cebral, M.A. Castro, O. Soto, R. Lohner and N. Alperin, Blood-flow models of the circle of Willis from magnetic resonance data, Journal of Engineering Mathematics 47 (2003), 369-386.

[5] A.W.J. Hoksbergen, C.B.L. Majoie, F.J.H. Hulsmans and D.A. Legemate, Assessment of the collateral function of the circle of Willis: Three-dimensional time-of-flight MR angiography compared with transcranial color-coded duplex sonography, American Journal of Neuroradiology 24 (2003), 456-462.

[6] F. Cassot, V. Vergeur, P. Bossuet, B. Hillen, M. Zagzoule and J.P. MarcVergnes, Effects of anterior communicating artery diameter on cerebral hemodynamics in internal carotid artery disease, Circulation 92 (1995), 3122-3131.

[7] B. Hillen, H. Hoogstraten and L. Post, A mathematical model of the flow in the circle of Willis, Journal of Biomechanics 19 (1986), 187-194.

[8] K.T. Moorhead, C.V. Doran, J.G. Chase and T. David, Lumped parameter and feedback control models of the auto-regulatory response in the circle of Willis, Computer Methods in Biomechanics and Biomedical Engineering 7 (2004), 121-130.

[9] A. Viedma, C. Jimenez and V. Marco, Extended willis circle model to explain clinical observations in periorbital arterial flow, Journal of Biomechanics 30 (1997), 265-272.

[10] F. Liang, K. Fukasaku, H. Liuand and S. Takagi, A computational model study of the influence of the anatomy of circle of willis on cerebral hyperperfusion following carotid artery surgery, Biomedical Engineering Online 10 (2011), 84-105.

[11] M. Olufsen, H. Tran and J. Ottesen, Modeling cerebral blood flow control during posture change from sitting to standing, Cardiovascular Engineering: An International Journal 4 (2004), 47-58.

[12] K.N. Kayembe, M. Sasahara and F. Hazama, Cerebral aneurysms and variations in the circle of Willis, Stroke 15 (1984), 846-850.

[13] A.P. Avolio, Multi-branched model of the human arterial system, Medical \& Biological Engineering \& Computing 18 (1980), 709-718.

[14] X. Li, J. Bai, S. Cui and S. Wang, Simulation study of the cardiovascular functional status in hypertensive situation, Computers in Biology and Medicine 32 (2002), 345-362.

[15] C. Zhang, L. Wang, X. Li, S. Li, F. Pu and D. Li, Modeling the circle of Willis to assess the effect of anatomical variations on the development of unilateral internal carotid artery stenosis, Bio-Medical Materials and Engineering 24 (2004), 491-499.

[16] J. Alastruey, K.H. Parker, J. Peiro, S.M. Byrd and S.J. Sherwin, Modeling the circle of Willis to assess the effects of anatomical variations and occlusions on cerebral flow, Journal of Biomechanics 40 (2007), 1794-1805.

[17] D.R. Craig, K. Meguro, C. Watridge, J.T. Robertson, H.J. Barnett and A.J. Fox, Intracranial internal carotid artery stenosis, Stroke 13 (1982), 825-828.

[18] D.J. Marzewski, A.J. Furlan, P.S. Louis, J.R. Little, M.T. Modic and G. Williams, Intracranial internal carotid artery stenosis: Longterm prognosis, Stroke 13 (1982), 821-824.

[19] J. Alastruey, S.M. Moore, K.H. Parker, T. David, J. Peiro and S.J. Sherwin, Reduced modeling of blood flow in the cerebral circulation: Coupling 1-D, 0-D and cerebral auto-regulation models, International Journal for Numerical Methods in Fluids 56 (2008), 1061-1067. 
[20] K.T. Moorhead, C.V. Doran, J.G. Chase and T. David, Lumped parameter and feedback control models of the auto-regulation response in the circle of willis, Computer Methods in Biomechanics and Biomedical Engineering 7 (2006), 121-130. 